\title{
How Can Health System Efficiency Be Improved in Canada?
}

\section{Comment peut-on améliorer l'efficience des systèmes de santé au Canada?}

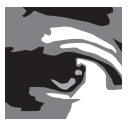 \\ SARA ALLIN, PHD \\ Canadian Institute for Health Information \\ Institute of Health Policy Management and Evaluation, University of Toronto \\ Toronto, ON \\ JEREMY VEILLARD, PHD \\ Canadian Institute for Health Information \\ Institute of Health Policy Management and Evaluation, University of Toronto \\ Toronto, ON \\ LI WANG, MA \\ Canadian Institute for Health Information, Toronto \\ Centre for Health Economics and Policy Analysis, McMaster University \\ Hamilton, ON \\ MICHEL GRIGNON, PHD \\ Centre for Health Economics and Policy Analysis, McMaster University \\ Hamilton, ON
}




\begin{abstract}
Improving value for money in the health system is an often-stated policy goal. This study is the first to systematically measure the efficiency of health regions in Canada in producing health gains with their available resources, and to identify the factors that are associated with increased efficiency. Based on the objective elicited from decision-makers that the health system should ensure access to care for Canadians when they need it, we measured the efficiency with which regions reduce causes of death that are amenable to healthcare interventions using a linear programming approach (data envelopment analysis). Variations in efficiency were explained in part by public health factors, such as the prevalence of obesity and smoking in the population; in part by characteristics of the population, such as their average income; and in part by managerial factors, such as hospital readmissions.
\end{abstract}

\title{
Résumé
}

Lamélioration de l'optimisation des ressources dans les systèmes de santé est un des objectifs souvent énumérés dans les politiques. Cette étude est la première à mesurer systématiquement, parmi les régions sanitaires au Canada, l'efficience de l'utilisation des ressources disponibles pour obtenir des gains sur le plan de la santé, et à déterminer les facteurs associés à un accroissement de l'efficience. En fonction des objectifs établis par les décideurs, à l'effet que le système de santé devrait pouvoir assurer l'accès aux soins pour les Canadiens au moment où ils en ont besoin, nous avons mesuré l'efficacité avec laquelle les régions parviennent à réduire les causes de décès attribuables à des interventions, et ce, au moyen de la programmation linéaire (méthode d'enveloppement des données). Les variations dans l'efficience sexpliquent en partie par des facteurs liés à la santé publique, tels que la prévalence de l'obésité et le tabagisme; en partie par les caractéristiques de la population, telles que le revenu moyen; et en partie par des facteurs liés à la gestion, tels que les réadmissions à l'hôpital.

\section{1 nnual spending on healthcare represented an estimated it. $2 \%$ of $\triangle$ annual income (gross domestic product, GDP) in 2013 in Canada, compared to 7\% 2 in 1975 (CIHI 2013b). This long-term trend of increasing spending on healthcare} is common to other industrialized countries; however, there is no clear relationship between high levels of spending on healthcare and improvements in health outcomes. For instance, Australia spent 9.1\% of its GDP on healthcare in 2011, while key indicators of health status improved at a faster pace and surpassed most indicators for Canada in the past 20 years (OECD 2014). The same holds true within Canada: the average resident of Alberta spends 23\% more than the average resident of Quebec on healthcare, without better health outcomes (CIHI 2013a, 2013b). It is therefore not surprising that questions would be raised about the value created by such expenditures. 
The goals of doing more with resources available are recognized by federal and provincial governments, and professional organizations alike, as a priority for ensuring the sustainability of the Canadian health system (CMA 2010; Health Canada 2013; MOHLTC 2012). This view is also shared by Canadians: a recent public survey placed efficiency higher than increased funding as priorities for health system reform (Environics Research Group 2011).

In the past few years, national and international experts, professional organizations and policy makers across the country have made numerous recommendations for reducing waste and improving efficiency in healthcare, for the most part by improving the way services are organized and delivered (Ontario Ministry of Finance Commission on the Reform of Ontario's Public Services 2013; The Council of the Federation 2012). However, to date, there has not been any attempt to measure systematically what expenditures buy in the Canadian healthcare system, nor to identify factors associated with higher levels of efficiency. Still, measuring health system efficiency has been the focus of several high-profile international studies, but these have limited application for decision-makers in general and have had limited impact in Canada (Joumard et al. 2010; WHO 2000). Among other issues, these studies make use of national indicators of the organization of healthcare (such as payment schemes or financing mechanisms) that do not take into consideration Canada's highly decentralized responsibility for healthcare delivery and administration.

This paper presents the results of a study that measured health system efficiency in Canada at the health region (sub-provincial) level (CIHI 2014). The aim of this study was to provide actionable results for decision-makers by identifying some of the factors that are associated with higher levels of efficiency. The focus was on technical efficiency, which refers to the extent to which objectives are achieved by health systems given available resources: it addressed the question of whether we could get more given what we spend. It is important to note that we use efficiency in a neutral sense here, referring to the ability of a health region to get more outcomes with the same level of resources; such ability can be the result of better management in the health region, but it can also result from environmental constraints beyond their control. Through the systematic measurement of health system outputs and inputs, we were able to measure inefficiencies in each region in Canada, and based on these findings, we gained insight into the factors explaining inefficiencies and the interplay among environmental, public health and managerial factors influencing efficiency.

\section{Methods}

In this study, the unit of analysis of health system efficiency was the health region. There are over 100 health regions in Canada, and this study included 89 regions for which data were available (territories were not included). Health regions are administrative bodies that are legislated by the provincial ministries of health. Even though the legislated roles of health regions, and their relationship with local hospitals and other providers, vary across provinces, health regions have a degree of responsibility (relative to the province where they are located) for improving the health of their respective populations. They are also responsible for 
providing health and healthcare services to their populations. There are important variations across regions that may affect efficiency, for instance in terms of the size and characteristics of the populations they serve, the range of resources available (CIHI 2013a; Statistics Canada 2013) and the strategies they adopt to coordinate and plan services for their populations. In 2010, the average population size of health regions in this study was over 400,000 people, with a range from 26,400 (Zone 5 in New Brunswick) to nearly 2 million (Région de Montréal, Québec).

This research proceeded in three steps. The first step was to define the objective (output) and resources (inputs) of the healthcare system. In the existing literature on health system efficiency we could identify, researchers often defined health systems objectives and resources on the basis of data availability. We were not able to identify studies that attempted to confirm whether decision-makers or citizens accepted these assumptions about what the healthcare system should be measured against. In contrast, in this study, we solicited decision-maker and other stakeholder perspectives, through a scoping review of public documents (archival work); a series of in-depth, qualitative, open-ended interviews with senior Canadian health ministry officials (Abelson and Pasic 2013); and, finally, a facilitated dialogue (which is akin to a focus group) with health system leaders and stakeholders (Lavis 2013). In the second step of this study, we gathered regional data on what these stakeholders had indicated were legitimate outputs and inputs from their perspective, and we calculated efficiency scores using a sophisticated version of a common approach in the health economics literature - data envelopment analysis (DEA). DEA uses linear programming that determines that a region is inefficient when any linear combination of observed regions yields more output with the same level of inputs (Jacobs et al. 2006). It simply describes the data, as opposed to assuming any specific relationship between the inputs and outputs as required for regression-based approaches such as stochastic frontier analysis. Not imposing any relationship gives DEA the advantage that it is less prone to misspecification bias than regression-based approaches. The weakness of the standard DEA, however, is that it has no stochastic component (it is entirely deterministic) and, as a result, imposes an assumption that at least some regions must be perfectly efficient (scores of 1). To alleviate this, we used a recently developed methodological improvement based on a procedure akin to a bootstrap analysis. Following bootstrapping, although no region attains a score of 1 , an efficiency score of 0.8 would still be interpreted as $80 \%$ efficient because it relates to the maximum attainable efficiency as opposed to the maximum observed efficiency score.

The last (third) step in this study was to conduct a regression analysis of the logarithm of the efficiency scores for each region on a set of explanatory variables to identify the factors that were significantly associated with variations in efficiency scores across regions. We used a backward step-wise regression to select variables to be included in the final regression model. 


\section{Data}

There are three main components to an efficiency analysis: the inputs (system resources) and the output (or system objective) of the healthcare system, which were used to calculate efficiency scores using DEA, and the factors that can explain how well inputs are used to produce the output, which were included in the third step-wise regression on efficiency scores. All data were ecological and measured at the level of the health region.

Based on the results of the qualitative study of stakeholder perspectives on the healthcare system, we defined the output, or objective, of the healthcare system as ensuring that Canadians have access to timely and effective healthcare when they are sick or need care. The concept of avoidable mortality provides the closest measurable indicator of this stated objective, as it measures the outcome of timely and effective healthcare being received (CIHI 2012b; Nolte and McKee 2004, 2008). Other possible measures of accessibility include waiting times and self-reported unmet need. Indicators such as these provide a partial picture of effective healthcare being received. Moreover, these indicators can be considered to be included in a summary measure like avoidable mortality, as longer wait times and other barriers to accessing appropriate care can help to explain why we observe premature deaths from treatable causes. Avoidable mortality can be divided into two components: causes of death that should have been prevented with effective public health interventions (e.g., vaccine-preventable deaths and smoking-related deaths) and causes of death that should have been treated with effective healthcare interventions. Some examples of treatable causes of death include sepsis, pneumonia, colorectal cancer, breast cancer in women, hypertensive diseases, asthma and most other respiratory diseases, renal failure, pregnancy and childbirth (CIHI 2012b). For this study we used the treatable potential years of life lost (PYLL), an indicator that calculates the number of years of life that are lost prematurely (here, before age 80) to causes of death that are considered to be treatable by healthcare interventions (CIHI 2012b; Nolte and McKee 2004, 2008). The underlying idea is that if Canadians had access to timely care when they need it, no person should die before age 80 of (the small set of) causes of death that are considered to be treatable. In practice, this means that a person who died at age 65 from a treatable cause of death would have lost 15 potential years of life. These values of the difference between the actual age of death and age 80 are then summed over the population and divided by the population count.

The choice of age 80 as the cut-off for considering a death to be premature was based on stakeholder feedback, in large part owing to the observation that about half of all deaths occur after age 80. However, sensitivity analyses were conducted using different cut-offs, including the conventional cut-off of 75 . Sensitivity analyses using an alternative measure of treatable mortality - the age-standardized mortality rate from treatable causes of death - were also conducted. Results were robust to these changes in both the age cut-off and the choice of mortality rate versus the years of life lost. 
In contrast to what we found in the stakeholder consultation, the majority of studies of efficiency have chosen measures of average population health, such as improving life expectancy or disability-adjusted life expectancy, and reducing infant mortality as the desired objective of the health system (CIHI 2012a). Only one other study that we identified measured efficiency across OECD countries in terms of reducing avoidable mortality (Joumard et al. 2010).

Also based on stakeholders perspectives, inputs were measured as the dollar value spent on the major components of healthcare: hospital costs, physician payments, pharmaceutical spending, cost of residential care facilities and community care. Spending data were from the Canadian Institute for Health Information administrative databases (the Canadian MIS database for hospital spending and the National Physicians Database for physician spending), Statistics Canada (the Residential Care Facility Survey and the 2006 Census to estimate spending on community care) and IMS Brogan Canada (community prescription drug spending). It is important to note that the estimates of hospital and specialist spending at the regional level were adjusted to account for the fact that residents of more rural regions likely travel to nearby urban regions that have more hospitals. Specifically, hospital and specialist spending were both divided by a modified version of the inflow-outflow ratio produced by the Canadian Institute for Health Information that accounted also for the average cost of delivering care in the region (using the average cost per in-patient) (CIHI 2014).

The environment in which a health system operates can significantly affect its ability to bring about health improvements with a given set of resources (Jacobs et al. 2006). For instance, the prevalence of health conditions that are considered to be amenable to health system interventions, such as asthma or pneumonia, can be affected by broader health determinants, such as education level. This study controlled for three external determinants of health - education level, and concentration of recent immigrants and individuals identifying as Aboriginal - by including them as additional inputs in the analysis. These three external determinants of health were chosen on the basis that they could be considered outside of the control of health system managers, and that they were significantly associated with the outcome measure (treatable PYLL). This ensured that comparisons were made only among health regions with similar operating environments.

Table 1 provides the mean, dispersion and range of inputs and outputs included in the calculation of the efficiency scores. 
TABLE 1. Description of variables included in the DEA

\begin{tabular}{|c|c|c|c|c|}
\hline & \multirow[b]{2}{*}{ Mean } & \multirow{2}{*}{$\begin{array}{l}\text { Standard } \\
\text { deviation }\end{array}$} & \multicolumn{2}{|c|}{ Range } \\
\hline & & & Minimum & Maximum \\
\hline \multicolumn{5}{|l|}{ Inputs - spending per capita, \$ } \\
\hline Hospitals & $1,718.93$ & 520.40 & 951.32 & $3,826.39$ \\
\hline Prescription drugs & 545.60 & 123.50 & 288.53 & 884.25 \\
\hline Physicians & 471.15 & 122.42 & |77.01 & 816.72 \\
\hline Residential care facilities & 336.42 & 164.00 & 74.20 & 901.83 \\
\hline Community nurses & 54.49 & $|8.5|$ & 19.59 & 98.68 \\
\hline \multicolumn{5}{|l|}{ Inputs - environment } \\
\hline Education (\% with high school or more) & 82.33 & 6.85 & 63.30 & 94.00 \\
\hline Recent immigrants (\%) & 3.16 & 4.21 & 0.10 & 16.70 \\
\hline Non-Aboriginal (\%) & 92.74 & 9.21 & 49.50 & 99.60 \\
\hline \multicolumn{5}{|l|}{ Output } \\
\hline $\begin{array}{l}\text { PYLL from treatable causes (before age } 80 \text { ), per 100,000 } \\
\text { population, age-standardized }\end{array}$ & $1,666.34$ & 317.92 & 1,066.6 & $2,452.6$ \\
\hline
\end{tabular}

Finally, the factors that were considered in the third step of the analysis (factors explaining efficiency scores) included the characteristics of the environment that are not adjusted for in the calculation of efficiency scores. These include the age and sex structure of the population, because they were not significantly associated with the outcome measure, which is not surprising given that treatable PYLL is age-standardized. Also considered were public health factors that could affect efficiency (such as the level of smoking and obesity in the population, and the proportion of the population reporting to have three or more chronic conditions), which reflect both past investments in health system as well as the current challenges that health system managers face. By not including these public health factors as inputs in the calculation of efficiency scores with DEA, the implication is that the prevailing burden of disease in the regions is within the responsibility of health system leaders. Moreover, variations in the population health of regions may then help to explain variations in the efficiency with which regions are able to transform health system dollars into health gains, as measured by fewer treatable causes of death. The remaining factors included those that are directly within the control of health system managers, such as hospital readmissions and lengths of stay. Table 2 provides the mean, dispersion and range of the variables that were considered in the step-wise regression analysis of efficiency scores. 
Sara Allin et al.

TABLE 2. Description of variables considered in the step-wise regression analysis

\begin{tabular}{|l|l|l|l|l|l|l|}
\hline \multicolumn{2}{|l|}{} & \multicolumn{1}{l}{ Mean } & \multicolumn{1}{l|}{$\begin{array}{l}\text { Standard } \\
\text { deviation }\end{array}$} & \multicolumn{2}{l|}{ Minimum } & Maximum \\
\hline Environmental factors & 0.5 & 0.01 & 0.48 & 0.52 \\
\hline Men & 0.14 & 0.03 & 0.08 & 0.22 \\
\hline Population aged 65 years and older & 249.08 & 896.03 & 0.13 & $5,679.00$ \\
\hline Population density & 4.1 & 2.85 & 1.3 & 16 \\
\hline Long-term unemployment & 32,164 & 5,287 & 23,611 & 50,111 \\
\hline Average income (\$) & 0.02 & 0.01 & -0.02 & 0.05 \\
\hline Income-related inequality in likelihood of a physician visit & 0.26 & 0.14 & 0.04 & 0.65 \\
\hline Income inequality (Gini index) & 0.8 & 0.4 & 0 & 1 \\
\hline No teaching hospitals in the region & &
\end{tabular}

\section{Public health factors}

\begin{tabular}{|l|l|l|l|l|}
\hline Daily smoking (per cent of population aged I2 and over) & 18.78 & 3.59 & 10.3 & 26.6 \\
\hline Obese (per cent of population aged I8 and over) & 19.91 & 5.06 & 6.3 & 30.8 \\
\hline Overweight (per cent of population aged I8 and over) & 35.65 & 3.31 & 23.7 & 43.7 \\
\hline $\begin{array}{l}\text { Three or more chronic conditions (per cent of population aged I2 and } \\
\text { over) }\end{array}$ & 24.34 & 3.7 & 16.5 & 32.2 \\
\hline Physically inactive (per cent of population aged I2 and over) & 49.16 & 5.85 & 29.4 & 61.3 \\
\hline
\end{tabular}

\section{Management factors}

\begin{tabular}{|l|l|l|l|l|}
\hline ACSC admissions per 100,000 population & 415.66 & 151.74 & 185.67 & 880.33 \\
\hline $\begin{array}{l}\text { Repeat hospitalizations for mental illness (per cent of patients with at least } \\
\text { one hospitalization for mental illness) }\end{array}$ & 10.93 & 2.68 & 4.1 & 18.1 \\
\hline C-sections (per cent of total births) & 23.58 & 7.04 & 0 & 37.36 \\
\hline VBAC rate (per 100 births) & 15.64 & 7.39 & 2.97 & 34.71 \\
\hline Overall 30-day readmission rate (per cent of all hospital discharges) & 9.33 & 1.84 & 6.24 & 15.96 \\
\hline 30-day readmissions (surgical) & 6.72 & 1.57 & 1.2 & 14.12 \\
\hline 30-day readmissions (paediatric) & 5.54 & 1.46 & 1.56 & 9.44 \\
\hline 30-day readmissions (medical) & 13.64 & 1.64 & 10.38 & 18.53 \\
\hline
\end{tabular}

\section{Operational factors}

\begin{tabular}{|l|l|l|l|}
\hline GPs (per cent of total physicians) & 63.75 & 14.37 & 34.53 \\
\hline Nursing in-patient services total worked hours per in-patient case & 50.99 & 7.43 & 39.63 \\
\hline Average typical length of stay in acute hospital (days) & 4.77 & 1.61 & 2.55 \\
\hline Average ALC length of stay in acute hospital (days) & 9.28 & 8.73 & 3.84 \\
\hline ALC cases (per cent total in-patient cases) & 4.86 & 5.52 & 0.45 \\
\hline Average occupancy rate in acute hospitals & 81.1 & 12.89 & 22.4 \\
\hline Average spending on administration as a per cent of total hospital spending & 5.32 & 1.68 & 33.4 \\
\hline Average cost per weighted case $(\$)$, acute hospitals & 5.123 .27 & 711.34 & 3.2 \\
\hline
\end{tabular}




\section{Results}

We found significant variations in health system efficiency across regions, even though comparisons were made only among regions that shared some key characteristics (in terms of concentration of recent immigrant, educated and Aboriginal populations). On average, the level of efficiency in Canada was 0.73 (compared with an optimal efficiency level set at 1.0), with a range across different model specifications between 0.65 and 0.82 across the 84 regions included in the study (after excluding five regions that were statistical outliers). This suggests that PYLL from treatable causes of death could be reduced by between $18 \%$ and $35 \%$ if all regions were operating efficiently in Canada. Figure 1 reports the efficiency scores summarized by province, showing a wide range of efficiency scores within every province (or group of provinces in the case of Atlantic Canada), with only British Columbia showing relatively higher scores than the rest of the country.

FIGURE 1. Summary of efficiency scores by province, including median, 25th and 75th percentiles (the number of regions in parentheses)

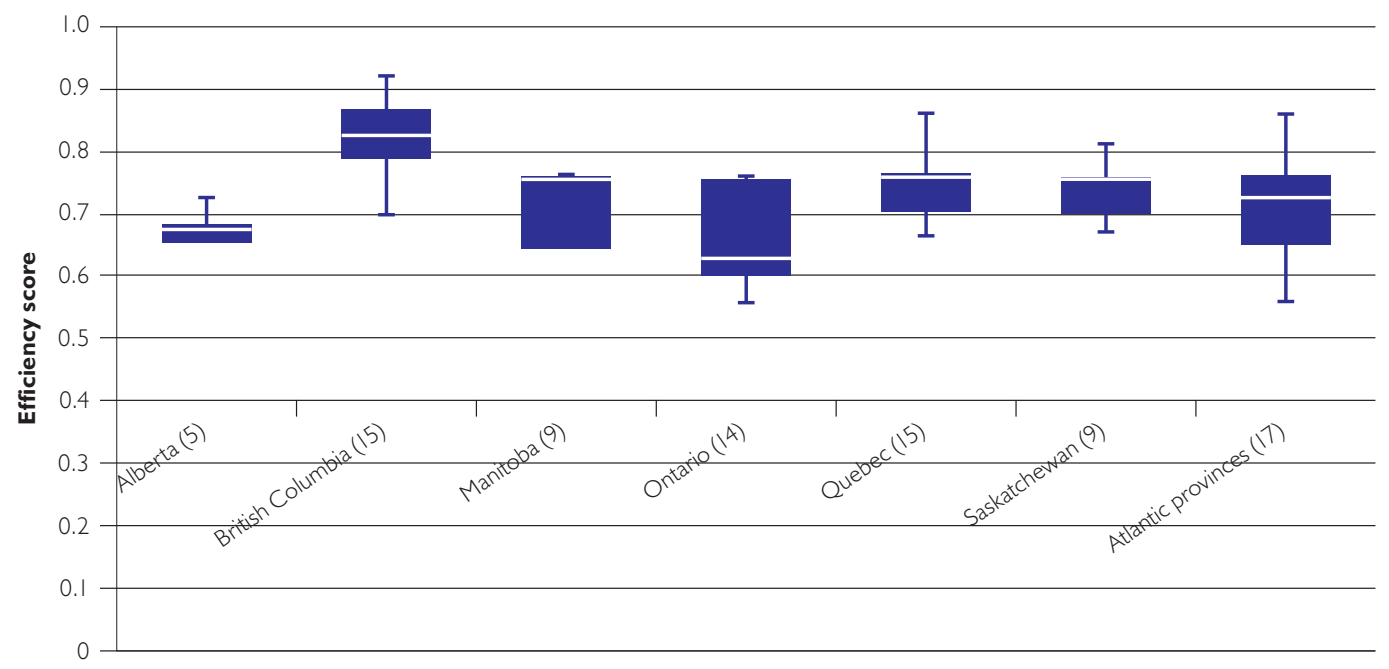

Note: Atlantic provinces include Newfoundland, New Brunswick, Nova Scotia and Prince Edward Island

Table 2 reports the results of the step-wise regression on efficiency scores. The regression results suggest that the variations in efficiency scores across regions relate in part to public health factors (here, measured by the prevalence of traditional risk factors for common diseases) and in part to more managerial factors related to the appropriate use of hospitals (e.g., Alternate Level of Care length of stay), hospital readmissions and investment in nurses and primary care physicians. Two of the environmental factors were also significantly (negatively) associated with efficiency: the average income of the population (richer regions use resources less efficiently) and the level of income-related inequity in the use of physician services in the region (regions that make sure the lower-income families can access services according to 
their needs have fewer deaths from treatable causes). It is important to note that sensitivity analyses indicated the results presented here were robust to alternative model specifications (CIHI 2014) (Table 3).

TABLE 3. Results of the regression on the logarithm of efficiency scores

\begin{tabular}{|c|c|c|c|}
\hline Variables & Coefficient & Standard. error & $P>|t|$ \\
\hline \multicolumn{4}{|l|}{ Contextual factors } \\
\hline Average income (logarithm) & $-0.304 *$ & 0.098 & 0.003 \\
\hline Inequity in the likelihood of visiting a physician in past 12 months & $-1.737 * *$ & 0.862 & 0.047 \\
\hline \multicolumn{4}{|l|}{ Clinical factors } \\
\hline Daily smoking (\%) & $-0.010 * *$ & 0.004 & 0.015 \\
\hline Physical inactivity (\%) & $-0.007 *$ & 0.002 & 0.004 \\
\hline Multiple (three or more) chronic conditions (\%) & $-0.013^{*}$ & 0.004 & 0.001 \\
\hline 30-day overall readmission (rate per 100) & $-0.021 * *$ & 0.009 & 0.028 \\
\hline \multicolumn{4}{|l|}{ Operational factors } \\
\hline GPs (\% of all physicians) & $0.005 *$ & 0.001 & 0.000 \\
\hline ALC length of stay (days) & $-0.002 *$ & 0.001 & 0.003 \\
\hline
\end{tabular}

*Significant at $p<0.01$

**Significant at $p<0.05$

\section{Discussion}

This study was the first to measure the level and determinants of health system efficiency in Canada based on quantitative and qualitative research involving key decision-makers. The findings suggest that significant health improvements could be gained without additional spending, and that some of the factors that could help bring about efficiency gains include interventions targeting the health of the population, such as reducing smoking and physical inactivity, as well as policies directed at the organization and delivery of health services, such as reducing hospital readmissions, or reducing length of hospital stay among patients designated as alternate level of care patients.

The range of efficiency scores that this study yielded is consistent with the (few) international studies that have included Canada. For instance, a recent OECD study found the level of inefficiency in Canada to be 20\% (Joumard et al. 2010). Moreover, we found that health systems operating in populations with poorer risk factors (smoking, obesity, inactivity) were less efficient. In other words, these findings indicate that more money is being spent in these regions to treat a more complex population, but outcomes are worse than in other regions with healthier populations. These results suggest that system managers can bring about 
improvements in value for money by addressing some of the important causes of illness and treatable conditions through targeted prevention efforts. This suggestion is consistent with reports and consultations stressing the importance of these determinants of health (CMA 2013; Lalonde 1974).

In addition, this study confirms the important role of organizational factors in achieving efficiency gains (Ontario Ministry of Finance Commission on the Reform of Ontario's Public Services 2013): reducing alternate level of care days and readmissions helps the health system managers direct healthcare dollars to more effective treatments to reduce causes of death due to treatable conditions, thereby improving efficiency. The findings from this study suggest that marginal investments in primary care may be more efficient than marginal investments in specialized care. This is consistent with the literature on the efficacy of primary care services (Marmot et al. 2008; Starfield et al. 2005; WHO 2008).

Interestingly, the study found that efficiency and equity may work in the same direction: because individuals with lower income need more care, on average, ensuring that these populations access primary care may be a good way of increasing efficiency. This finding is in line with the literature on equity and recent debates about health financing and universal health coverage suggesting that healthcare should be distributed according to need, not ability to pay (Marmot et al. 2008).

There are several strengths to this study that are worth noting. First, the theoretical model of health system efficiency we used was informed by stated preferences of decision-makers who are responsible to take action on the findings. Second, we were able to use extensively a wealth of data on spending and outcomes, even though there were still some limitations. Third, the sensitivity analyses we conducted showed that the study results were robust to changes in model specifications, such as to changes to the age cut-off for defining premature death, and to the choice of outcome measure as PYLL versus the age-standardized mortality rate from treatable causes of death. Finally, we were successful at estimating relative levels of inefficiency and explaining a significant portion of the variations observed.

However, there were also some important limitations to this study. First, the variables included in the final regression model accounted for just half of the variation in efficiency scores. The unexplained variation could relate to population characteristics that we were not able to measure and/or to indicators of clinical practice and system management that are difficult to measure with existing data sources. Second, with existing limitations in timeliness of mortality data in Canada, we were only able to measure health system efficiency at one point in time and with historical data. Third, the outcome measure we used in this study included only deaths and not a measure of health and well-being. Finally, we encountered some challenges in measuring spending in all categories of health system expenditures (e.g., public health spending is not easily measured at the regional level), and in measuring physician spending given the increasing role of alternative payments. 


\section{Conclusions}

A major conclusion of this study is that any policy action aiming at reducing the efficiency gap needs to include both interventions related to traditional sources of inefficiency and those focused on the prevention of disease and health promotion interventions. Practically, an implication for provincial and territorial governments in Canada is that focusing on operational efficiency and indicators of good management will not substantially reduce the efficiency gap measured. A diversity of interventions on healthcare services, health promotion and disease prevention and broader determinants of health is required to improve efficiency. In addition, the results suggest that investments in primary care and advanced access to healthcare services for lower-income individuals may be effective in improving health system efficiency.

There are several avenues for future research that could improve our understanding of efficiency in Canada. These include improving our understanding of how some health regions have achieved higher efficiency scores than other regions, for instance, with in-depth qualitative analysis such as case studies. It would also be important to better capture some of the factors that may affect efficiency that we cannot easily measure at present, such as indicators of management style, workplace conditions and patient experience. Finally, future research could consider including morbidity variables (e.g., the Health Utilities Index) in the model of efficiency to capture the impact of the health system on quality of life in addition to more readily available measure of quantity of life (e.g., with measures of years of life lost).

\section{Acknowledgements}

This study was funded by the Canadian Institute for Health Information (CIHI).

The authors are grateful for the support and contributions by several CIHI staff, in particular by Diana Ridgeway, Program Lead, and Jean Harvey, Director of the Canadian Population Health Initiative.

Correspondence may be directed to: Sara Allin; e-mail:sara.allin@utoronto.ca.

\section{References}

Abelson, J. and D. Pasic. 2013. Health System Efficiency Project: A Qualitative Study of Provincial and Territorial Health Ministry Perspectives. Ottawa: Canadian Institute for Health Information.

Canadian Institute for Health Information (CIHI). 2012a. Developing a Model for Measuring the Efficiency of the Health System in Canada. Ottawa: Canadian Institute for Health Information.

Canadian Institute for Health Information (CIHI). 2012b. Health Indicators 2012. Ottawa: Canadian Institute for Health Information.

Canadian Institute for Health Information (CIHI). 2013a. Health Indicators 2013. Ottawa: Canadian Institute for Health Information.

Canadian Institute for Health Information (CIHI). 2013b. National Health Expenditure Trends, 1975-2013.

Ottawa: Canadian Institute for Health Information.

Canadian Institute for Health Information (CIHI). 2014. Measuring the Level and Determinants of Health System Efficiency in Canada. Ottawa: Canadian Institute for Health Information. 
Canadian Medical Association (CMA). 2010. Health Care Transformation in Canada: Change That Works, Care That Lasts. Ottawa: Canadian Medical Association.

Canadian Medical Association (CMA). 2013. Canadian Medical Association (2013) Health Care in Canada: What Makes Us Sick? Ottawa: Canadian Medical Association.

Environics Research Group. 2011. “Canadians Feel Improving the Health Care System Lies with Addressing Inefficient Management Over Expanding Funding." Retrieved January 30, 2014. <http://www.environics.ca/newsand-insights?news_id $=110>$.

Health Canada. 2013. Minister Ambrose Addresses the 146th Canadian Medical Association Meeting - Working Together for Real Outcomes. Retrieved February 1, 2014. <http://news.gc.ca/web/article-en.do?nid=765229>. Jacobs, R., P.C. Smith and A. Street. 2006. Measuring Efficiency in Health Care: Analytic Techniques and Health Policy. Cambridge: Cambridge University Press.

Joumard, I., P. Hoeller, C. André and C. Nicq. 2010. Health Care Systems: Efficiency and Policy Settings. Paris: Organisation for Economic Co-operation and Development.

Lalonde, M. 1974. A New Perspective on the Health of Canadians. Ottawa: Government of Canada.

Lavis, J.N. 2013. Dialogue Summary: Measuring Health System Efficiency in Canada. Hamilton: McMaster Health Forum.

Marmot, M., S. Friel, R. Bell, T.A. Houweling and S. Taylor. 2008."Closing the Gap in a Generation: Health Equity through Action on the Social Determinants of Health." Lancet 372(9650): 1661-69. doi: S01406736(08)61690-6.

Nolte, E. and M. McKee. 2004. Does Healthcare Save Lives? Avoidable Mortality Revisited. London: The Nuffield Trust.

Nolte, E. and M. McKee. 2008. "Measuring the Health of Nations: Updating an Earlier Analysis." Health Affairs 27(1): 58-71

OECD. 2014. OECD Health Data. Paris: Organisation for Economic Co-operation and Development.

Ontario Ministry of Finance Commission on the Reform of Ontario's Public Services. 2013. Public Services for Ontarians: A Path to Sustainability and Excellence. Toronto: Queen's Printer for Ontario.

Ontario Ministry of Health and Long-Term Care (MOHLTC). 2012. Ontario's Action Plan for Health Care.

Toronto: Queen's Printer for Ontario.

Starfield, B., L. Shi, A. Grover and J. Macinko. 2005. "The Effects of Specialist Supply on Populations' Health: Assessing the Evidence." Health Affairs (Suppl Web Exclusives): W5-97-W95-107.

Statistics Canada. 2013. Health Profile. Retrieved January 30, 2014. <http://www12.statcan.gc.ca/healthsante/82-228/>.

The Council of the Federation. 2012. From Innovation to Action: The First Report of the Health Care Innovation Working Group. Ottawa: The Council of the Federation.

World Health Organization (WHO). 2000. The World Health Report 2000: Health Systems: Improving Performance. Geneva: World Health Organization.

World Health Organization (WHO). 2008. The World Health Report 2008 - Primary Health Care (Now More Than Ever). Geneva: World Health Organization. 